\title{
Breve caracterização da imigração em Portugal
}

Paulo Estrela*

\section{RESUMO}

O objectivo deste texto é proceder a uma breve descrição do desenvolvimento do fenómeno migratório em Portugal, um país tradicionalmente de emigração, onde, nas últimas décadas, a população imigrante aumentou de forma muito significativa, espalhando-se pelas áreas urbanas, suburbanas e rurais.

Para tal, procedeu-se a uma pesquisa de informação sobre este processo na literatura de referência, no Google e num trabalho efectuado pelo autor.

Palavras-Chave: Fenómeno Migratório; Imigrantes; Portugal.

\section{INTRODUÇÃO}

$\mathrm{V}$ ive-se, presentemente, numa época em que se assiste a uma significativa diversificação da composição cultural e étnica da sociedade portuguesa, em resultado da instalação, no território nacional, de um número expressivo de imigrantes. Esta situação condiciona problemas específicos nas duas populações (autóctone e imigrante), sobretudo nos espaços metropolitanos, decorrentes do desconhecimento mútuo das particularidades culturais de cada uma, e das representações estereotipadas que lhes estão associadas.

Neste artigo procura-se dar a conhecer, de uma forma resumida, o modo como se iniciou, evoluiu e consolidou o fenómeno migratório com destino a Portugal, nas últimas décadas do século XX.

A deslocação de indivíduos entre diferentes territórios sempre constituiu um fenómeno habitual na evolução da humanidade, embora as causas que a determinaram tenham variado ao longo dos tempos. Recentemente, a globalização, o desemprego, a desorganização das economias tradicionais, as desigualdades económicas entre países e entre os hemisférios Norte e Sul, as guerras civis no Terceiro Mundo e as calamidades naturais, representaram os principais motivos para emigrar. $^{1}$

Como consequência, os países da União Europeia (UE) têm assistido a uma progressiva alteração do seu

*Chefe de serviço de Medicina Geral e Familiar, Centro de Saúde de Loures tecido social, fruto da existência de um número cada vez maior de grupos étnicos distintos no seu território, em alguns casos decorrente do seu passado colonial nos continentes africano, asiático e sul-americano. ${ }^{2}$

Actualmente, Portugal é um país de emigrantes e imigrantes, mas a presença expressiva de cidadãos estrangeiros, em solo português, só se iniciou com a chegada de um número significativo de refugiados após a perda da soberania portuguesa sobre os territórios indianos nos anos 60. Também na mesma década, devido ao início das guerras de libertação das colónias portuguesas em África, o Estado português procurou incentivar a formação académica de jovens das elites sociais destes territórios em Universidades portuguesas, contribuindo para uma maior visibilidade destes indivíduos, sobretudo nas principais cidades do país. ${ }^{2}$

Em virtue da presença de grandes contingentes militares na guerra colonial, e da emigração de um número importante de portugueses, os anos 70 iniciaram-se com Portugal forçado a recorrer a mão-de-obra exterior. Valendo-se, então, da sua condição de país colonizador, recrutou os trabalhadores de que necessitava nas suas possessões africanas, principalmente em Cabo Verde. $^{2-4}$

Já no final desta década, a chegada de imigrantes, sobretudo de origem africana e asiática, esteve muito relacionada com o processo de descolonização destes territórios e com a consequente instabilidade política e social que se verificava, então, nestes novos Estados independentes. $^{3}$ 
A vinda dos «Retornados» desempenhou um papel importante no aumento do número de indivíduos oriundos dos países de língua oficial portuguesa (PALOP) que emigraram posteriormente para Portugal, porque os primeiros desenvolveram redes sociais que ajudaram à instalação dos segundos. ${ }^{5}$

Nos anos seguintes iniciou-se um novo tipo de migração. Nessa época, a par do crescimento da economia portuguesa e de um aumento das oportunidades de emprego nas grandes obras públicas do Estado, resultante da entrada do país na UE, verificou-se, também, uma forte contracção à emigração para os países da Europa Central e do Norte, tradicionais empregadores de cidadãos estrangeiros. O que conduziu a uma grande pressão dos fluxos migratórios sobre os países do Sul da Europa, Portugal incluído. Assistiu-se, então, a uma entrada crescente em território português de mão-de-obra indiferenciada, para a construção civil (homens) e para os serviços de limpeza, industriais e domésticos (mulheres), principalmente oriundos dos PALOP, em resultado das afinidades culturais e da partilha de uma língua comum. ${ }^{5-7}$

Na sua maioria, apresentavam baixos níveis de qualificação escolar e profissional, nada adequados ao tipo de sociedade urbano-industrial que vinham encontrar em Portugal. Foram, assim, sendo empregados em trabalhos perigosos e socialmente desvalorizados, com vínculos laborais precários e onde auferiam salários reduzidos. Em oposição, os imigrantes de origem asiática ocupavam-se no pequeno comércio de base familiar e étnica e como vendedores ambulantes, embora uma minoria trabalhasse, também, na construção civil. ${ }^{4,5}$

À medida que foi aumentando este fluxo migratório, foi-se também alterando e diversificando o estatuto socioprofissional e o local de origem destas populações. É o caso da imigração de origem brasileira, inicialmente composta por profissionais altamente qualificados (nas áreas da estomatologia, jornalismo e publicidade e marketing), que passou a ser constituída, posteriormente, por indivíduos com pouca qualificação, que se empregaram na construção civil, comércio, hotelaria e restauração. Quanto à diversificação da área de partida assistiu-se, na década de noventa, à chegada de imigrantes provenientes de países da Europa de Leste/Sudeste, principalmente Ucrânia, Moldávia, Roménia e Rússia. Estes trabalhadores, embora geralmente deten- tores de qualificações técnicas intermédias, ou de formação superior, foram ocupar os mesmos trabalhos indiferenciados na construção civil e nas limpezas e, minoritariamente, na agricultura e em algumas indústrias transformadoras. ${ }^{5}$

Mais recentemente, constata-se um reforço significativo de imigrantes oriundos do Brasil para os sectores da construção civil, comércio, hotelaria e restauração, bem como um aumento da presença de cidadãos indianos e paquistaneses, que se dedicam ao pequeno comércio, e de chineses, estabelecidos, predominantemente, no sector da restauração e distribuição. ${ }^{5}$

Concomitantemente, e em virtude da internacionalização da economia portuguesa resultante da entrada de Portugal na UE e da captação de investimento estrangeiro, fixou residência no país outro grupo de trabalhadores, altamente qualificados, com estatuto socioprofissional diametralmente oposto aos anteriores. Ocupam cargos superiores nas áreas das ciências, tecnologias e gestão de empresas multinacionais com interesses económicos e financeiros em Portugal. A par destes, vários cidadãos europeus de escalões etários mais avançados e na situação de aposentados (na sua maioria britânicos, holandeses e alemães), também eles detentores de elevados recursos socioeconómicos, escolhem o país pelo seu clima ameno, para fixarem residência definitiva ou para permanecerem durante longos períodos de tempo. ${ }^{2,5}$

Deste modo, constata-se que a distribuição dos activos estrangeiros em Portugal está muito concentrada nos dois extremos do tecido social e do mercado de trabalho.?

Em virtude da presença destas populações, Portugal, que se apresentava como um país de identidade cultural uniforme e etnicamente homogéneo, ocupando uma área territorial bem definida, demarcada por fronteiras que se mantiveram estáveis durante oito séculos, e em particular a Área Metropolitana de Lisboa, exibem, actualmente, uma grande diversidade social, étnica, cultural e religiosa. O que representa uma modificação profunda no seu tecido social, que só tem paralelismo na conjuntura que se vivia nos séculos XV e XVI, em plena época da expansão marítima portuguesa, descrita por Fernão Lopes como um lugar de «muitas e variegadas gentes».

O país passou, assim, em quatro décadas, de fornecedor de mão-de-obra não qualificada, com quase cin- 
co milhões de emigrantes dispersos por todo o mundo, a um Estado onde, segundo Rosário Farmhouse (Alta Comissária para a Imigração e Minorias Étnicas), existem cento e cinquenta nacionalidades, representando cerca de cinco por cento da população residente e sete por cento da população activa. De acordo com os dados do Quarto Inquérito Nacional de Saúde à População Portuguesa esta população imigrante, em relação à autóctone, apresentava maior número de indivíduos do sexo masculino, de jovens e de trabalhadores activos.

Isto, porque a maioria da imigração com destino a Portugal se caracteriza pela intenção, à partida, de ser uma migração laboral temporária, frequentemente individual, pelo que é, geralmente, constituída predominantemente por homens. Porém, quando estes interiorizam a necessidade de manter esta situação por um período de tempo mais longo do que o previsto inicialmente, a separação dos restantes elementos do agregado familiar faz-se sentir intensamente, tornando-se, progressivamente, mais difícil de suportar. ${ }^{2}$

É nestas situações de grande sofrimento emocional que mais necessária se torna a protecção conferida pela célula familiar (em termos psicológicos, afectivos e mesmo económicos) pelo que a sua ausência, se mantida no tempo, pode agravar, sobremaneira, a situação de vulnerabilidade quase sempre presente no processo migratório. Para além de que a presença da mulher, no triplo papel de esposa, mãe e gestora doméstica, facilita a integração familiar e possibilita uma orientação e rentabilidade dos recursos, que permite uma melhor orientação das estratégias económicas da família. Como referido por Fonseca, $(2005: 12)^{5}$ «...sendo profunda a adversidade o melhor antídoto - psicológico, emocional, afectivo, mesmo económico-encontra-se na qualidade (e resiliência) da relação familian».

Assim, tendem a desenvolver-se correntes migratórias a partir do local de origem dos imigrantes, traduzidas pela vinda de familiares ao abrigo de políticas de reunificação familiar, ou recorrendo a imigração clandestina quando a privação de viver em família se eterniza, devido a causas meramente burocráticas ou administrativas. ${ }^{5}$

Mais recentemente, $\mathrm{o}$ acto de emigrar tornou-se fruto de uma decisão colectiva da família, enquadrando-se numa estratégia de melhoria das condições socio-económicas do agregado familiar. Esta determina a forma como se realiza o processo migratório quando surge essa oportunidade, e qual, ou quais, os elementos que migram para o local onde os salários auferidos são mais elevados. Nestes casos, os papéis associados ao género constituem um factor determinante nessa escolha, já que, quando existem crianças ou idosos a cargo, são, geralmente, as mulheres que ficam no país de origem, para prestar os cuidados necessários a estes elementos. Posteriormente, é novamente como um todo que a família opta entre a hipótese de permanecer no país de origem, beneficiando das remessas do ou dos indivíduos que emigraram, ou de se lhes reunir, quando dispõe dos meios ou da oportunidade para o fazer, nos casos em que se perspectiva um benefício acrescido, em termos afectivos ou financeiros, com essa decisão. ${ }^{5}$

No entanto, este processo migratório tradicional, baseado em redes sociais e familiares, tem vindo a modificar-se com o progressivo encerramento das fronteiras da UE à imigração, associado ao conceito da Europa Fortaleza. Actualmente, a reunificação familiar e o direito de asilo constituem, praticamente, as únicas vias de entrada legal no território da UE, dando azo ao aparecimento de um sistema de recrutamento e de tráfico de mão-de-obra, organizado por redes profissionais africanas ou da Europa de Leste/Sudeste. ${ }^{5}$

Como consequência, tem aumentado o número de imigrantes ilegais, apesar das iniciativas promovidas pelo Estado português durante os anos 90 para a sua legalização, desconhecendo-se, actualmente, a dimensão total do fenómeno da imigração clandestina associada a redes mafiosas, que estendem, também, os seus negócios ao mundo da droga e prostituição. ${ }^{2}$

Por essa razão, a presença de mulheres no processo migratório, fora do contexto do reagrupamento familiar, pode ser indiciador de se tratar de vítimas de redes de tráfico de mulheres com destino à prostituição, embora se constate, igualmente, um aumento do número de mulheres que emigram sozinhas, com base num projecto migratório autónomo. ${ }^{8}$

Recentemente, a dificuldade em conseguirem trabalho, bem como a situação de desemprego decorrente de despedimento, tem levado à saída de trabalhadores imigrantes em Portugal para outros países, a maior parte dos quais já com nacionalidade portuguesa adquirida. $^{7}$

Em Portugal, como na maior parte dos países anfi- 
triões, as comunidades de imigrantes concentram-se, sobretudo, na periferia das áreas metropolitanas das principais cidades e na faixa litoral, onde encontram maior facilidade de trabalho nos sectores da construção civil e obras públicas, nos serviços domésticos e de limpeza, no turismo e na restauração. Deste modo, o distrito de Lisboa apresenta-se, sob o ponto de vista étnico, como o mais heterogéneo de todo o país, seguido pelos distritos de Faro, Setúbal e Porto. Também com presença significativa, embora menor, surgem os distritos de Santarém, Aveiro e Coimbra, no território continental, e as Regiões Autónomas dos Açores e Madeira. No interior do país a presença é ainda pouco sentida, conquanto se tenha acentuado recentemente no Ribatejo, Alentejo e Região do Oeste, sobretudo devido à presença de imigrantes europeus extra-comunitários. ${ }^{5}$

A maior visibilidade social destas populações, resultado da sua presença crescente no espaço português, tem provocado problemas sociais importantes, pois são percepcionadas como uma ameaça à estabilidade e um factor de agravamento da criminalidade, em geral ou associada ao crime mais violento, conduzindo a um aumento de manifestações de carácter xenófobo e racista por parte da população autóctone. ${ }^{9}$

A comunicação social, sobretudo a imprensa escrita e a televisão, poderia desempenhar um papel importante na destruição destes preconceitos e estereótipos. Porém, como os critérios para dar determinada notícia se baseiam nas audiências esperadas, é fácil perceber porque é tratada, até à exaustão, qualquer notícia que identifique estas populações a práticas desviantes. ${ }^{9}$

Contudo, a situação demográfica que se verifica, actualmente, no espaço europeu, é caracterizada por uma diminuição acentuada da fecundidade geral, que já não permite a substituição das gerações, apesar do contributo das populações migrantes em que, geralmente, é elevado o número de nascimentos. Também o progressivo envelhecimento da população europeia, em consequência dos progressos obtidos pela medicina preventiva e curativa, da maior acessibilidade aos cuidados de saúde e da melhoria das condições de vida dos indivíduos, contribui para esta situação demográfica. As repercussões sociais, económicas e políticas já se começaram a fazer sentir (na redução do número de activos por cada idoso) e tenderão a aumentar, num futuro próximo, em virtude dos avultados encargos fi- nanceiros que a população activa terá de suportar, levando ao aparecimento de estereótipos contra os idosos com base na incapacidade física e inutilidade produtiva. ${ }^{10}$

Neste contexto, parece que só o recurso aos movimentos migratórios poderia ajudar a repor, em certa medida, o número de habitantes necessários ao equilíbrio demográfico da UE. ${ }^{11}$ É o conceito de «migração de substituição» que corresponde «...à la migration internationale dont un pays aurait besoin pour éviter le déclin et le vieillissement de sa population résultant de faibles taux de fécondité et de mortalité.» Grinblat (2001:27). ${ }^{12}$

Porém, recorrer à imigração para compensar totalmente os efeitos do envelhecimento demográfico não representa uma solução realista. Até porque estas populações também envelhecem e tendem, cada vez mais, a permanecer no país para onde emigraram, pelo que iria culminar numa situação idêntica à que se verifica presentemente. ${ }^{9}$

\section{REFERÊNCIAS BIBLIOGRÁFICAS}

1. Instituto Nacional de Saúde Dr. Ricardo Jorge. Departamento de Epidemiologia. A saúde dos imigrantes: Inquérito Nacional de Saúde 2005. Lisboa: Instituto Nacional de Saúde Dr. Ricardo Jorge; 2008.

2. Rocha-Trindade MB. Sociologia das Imigrações. Lisboa: Universidade Aberta; 1995.

3. Barreto A. A situação social em Portugal:1960-1995. Lisboa: Universidade de Lisboa; 1995.

4. Machado F,Abranches M. Caminhos limitados de integração social: trajectórias socioprofissionais de cabo-verdianos e hindus em Portugal. Sociologia, Problemas e Práticas 2005; 48: 69-91.

5. Fonseca ML, et al. Reunificação familiar e imigração em Portugal. Lisboa: Alto Comissariado para a Imigração e Minorias Étnicas; 2005.

6. Santos ML. As políticas culturais em Portugal: Relatório Nacional. Lisboa: Observatório das Actividades Culturais; 1998.

7. Pereira S. Trabalhadores imigrantes de origem africana: precaridade laboral e estratégias de mobilidade geográfica. Migrações 2008 Abr; 2: 47-71.

8. Monteiro AP. Imigração e Saúde - imigrantes da Europa de Leste em Portugal [online]. 2006. Disponível em: http://www.esenfc.pt/esen$\mathrm{fc} /$ admin/conteudos/downloadArtigo.php?id_ficheiro $=219 \&$ codigo $=$ [acedido em 06/11/2008].

9. Soares P.A promoção de saúde na infância em contexto multicultural [dissertação]. Lisboa: Universidade Aberta; 2003.

10. Carmo H, coord. Problemas Sociais Contemporâneos. Lisboa: Universidade Aberta; 2001.

11. Saúde e migrações na UE [online]. 2007. Disponível em: http:// www.portaldasaúde.pt/portal/conteúdos [acedido em 06/11/2008].

12. Grinblat JA. Europe: quel rôle possible pour les migrations de remplacement. Géopolitique: Revue de l'Institut International de Géopolitique $2001 ; 74:$ 26-32. 
ENDEREÇO PARA CORRESPONDÊNCIA

Paulo Estrela

Rua Alexandre Ferreira $n^{\circ} 307^{\circ}$ Dto

1750-011 Lisboa

Telef: 217575816

E-mail: pauloestrela@ sapo.pt

Recebido em 20/01/09

Aceite para publicação em 11/02/09

\section{ABSTRACT}

The aim of this text is to describe, briefly, the development of the migratory phenomenon in Portugal, a traditional country of emigration, where, in the last decades, immigrant population has increased significantly, sparing across urban, suburban and rural areas.

A literature search was conducted to seek information of this process in reference literature, in a computer database and in own researches.

Keywords: Migratory Phenomenon; Immigrants; Portugal. 